\title{
A GEMINAÇÃO DE CONSOANTES NO ITALIANO*
}

\section{- Luciana Pilatti Telles -}

RESUMO: This study presents an analysis on consonant gemination in Italian. The hypothesis that guides our analysis is that gemination is phonemic in Italian. Based on Autosegmental Phonology assumptions, we analyze the geminate representation as a double linking segment in this language, considering the blocking properties shown by this segment. To justify its as an underlyingly long segment, we consider its heterosilabic distribution, according to the onset and coda conditions in Italian. Concerning its prosodic constitution, we consider the hypotheses of Strong Rhyme Condition (Vogel, 1982; Chierchia, 1986), well-formedness feet condition, which expects bimoraic feet (D'Imperio \& Rosenthal, 1999), and quantity-sensitive stress assignment (Sluyters, 1990). Considering that stress in Italian is cyclic, any of the three hypotheses of the geminate prosodic configuration points to the conclusion that gemination is underlying in Italian. However, considering the fact that the syllabic and prosodic well-formedness hypotheses do not explain the gemination in non-stressed contexts, we believe that the best option to explain the relation between gemination and stress in this language is the consideration that the stress system in Italian is quantity-sensitive, as presented by Sluyters (1990).

PALAVRAS-CHAVE: Fonologia, Fonologia Autossegmental. Língua Italiana. Consoantes. Consoantes Geminadas. Acento.

\section{INTRODUÇÃO}

Neste trabalho, analisamos a geminação de consoantes no italiano de modo a verificar sua caracterização segmental enquanto consoante constituída por ligação dupla, de acordo com os pressupostos da Fonologia Autossegmental. Buscamos responder a algumas questões. São elas: 1) Em que momento ocorre a geminação? É fonológica ou se estabelece foneticamente? 2) Qual a relação entre acento e geminação? A geminação é motivada pelo acento ou a atribuição de acento é sensível à geminação? 3) Se o acento no italiano é sensível à estrutura da sílaba e a geminação ocorre pelo preenchimento de uma posição esqueletal, qual a especificação desta posição? Não poderia ser preenchida por traços de vogal? 4) Todas as geminadas no italiano são derivadas por regras ou há geminadas pré-especificadas?

De modo a responder às questões listadas acima, organizamos este artigo em três seções: a primeira referente à estrutura da geminada com base nos pressupostos da Teoria Autossegmental; a segunda referente à relação entre sílaba, acento e geminação no italiano; e a terceira sobre a natureza derivacional da geminada na língua italiana.

\section{A ESTRUTURA DA CONSOANTE GEMINADA}

De acordo com os pressupostos da Teoria Autossegmental, um dos princípios que governa a fonologia das línguas é o Princípio do Contorno Obrigatório, princípio segundo o qual segmentos idênticos não podem ser adjacentes a menos que constituam um segmento de ligação dupla; um segmento constituído por uma raiz e desenvolvido em dois tempos de duração. Para tanto, mostramos que as geminadas no italiano bloqueiam a aplicação de regras que fazem referência a segmentos simples, como as regras de inserção de epêntese e de palatalização, por exemplo. Expomos exemplos de dados no italiano em que a geminada não oferece bloqueio à aplicação de regras, o que pode ser justificado como um caso de atuação da Condição

Luciana Pilatti Telles é licenciada em Letras (português/ italiano) pela UFRGS e mestre em Teoria e Análise Lingüística pelo PPGLetras/UFRGS. Durante o curso de mestrado foi bolsista CAPES.

*Este trabalho é parte da dissertação orientada pela Profa. Dra. Valéria Neto de Oliveira Monaretto, apresentada em 29/05/2003, e argüida pelas professoras doutoras Gisela Collischonn, Carmen Matzenauer e Neires Paviani. 
de Aplicabilidade Uniforme, proposta por Schein \& Steriade (1986).

Quanto à sua distribuição na sílaba, consideramos que a geminada é heterossilábica no italiano - ou seja, parte de sua estrutura ocupa a coda da sílaba precedente e parte ocupa o ataque da sílaba seguinte - em respeito à condição de estrutura silábica da língua em análise. Quanto à relação entre geminação e acento, comparamos a proposta de Vogel (1982), que prevê a formação de geminadas em cumprimento à Condição de Constituinte Forte; a proposta de D'Imperio \& Rosenthal (1990), que justificam a geminação como respeito à condição de formação de pés bimoraicos; e a proposta de Sluyters (1990), que defende que o italiano seja uma língua de acento sensível à quantidade silábica. Defendemos aqui que o italiano seja uma língua de acento sensível ao peso silábico e acreditamos também que a geminação, ou as condições para que ocorra geminação, está disponível no léxico antes da atribuição do acento, não sendo a geminação provocada por ele.

A hipótese de que a geminada é fonológica pode ser sustentada parcialmente nos exemplos listados em (1), que mostram pares opositivos de consoantes duplas versus consoantes simples intervocálicas.

\section{(1)}

bella : bela 'bela, bale'

fatto : fato 'feito, destino'

sonno : sono 'sono, sou'

cappello : capello 'chapéu, cabelo’

Nos exemplos listados em (1), as palavras distinguem-se entre si por apresentarem ou não consoante geminada. Saltarelli (1970 e 1983), porém, considera a hipótese de que, nos dados apresentados em (1), a distinção entre as palavras ocorra em termos de vogais breves e vogais longas e não em termos de consoantes simples e consoantes geminadas. Entretanto, podemos acreditar que o contraste é percebido em relação à duração da consoante e não da vogal, tendo por base o fato de que - segundo as análises acústicas de Giovanardi \& Di Benedetto (1998), Mattei \& Di Benedetto (2000) e Faluschi \& Di Benedetto (2001) - a geminada apresenta maior duração em relação às consoantes e simples e até mesmo em relação às vogais longas. As geminadas são segmentos de maior duração e são assim reconhecidos pelos falantes de italiano, conforme alega Nespor (1993).

Se as análises acústicas demonstram que foneticamente as consoantes geminadas têm maior duração e que esta duração é maior em relação à duração das vogais longas, podemos acreditar que a geminada, fonologicamente, ocupe duas posições de tempo. Essas duas posições temporais podem ser mapeadas a um segmento de ligação dupla ou a dois segmentos de ligação simples. Acreditamos que se trate de um segmento de ligação dupla, ou seja, um segmento geminado, pois regras de epêntese e de mudança de traços de segmentos de ligação simples não se aplicam a segmentos geminados, conforme os dados que relacionaremos a seguir.

Com relação à inserção de vogal epentética, Sluyters (1990) nos mostra que a aplicação de epêntese tem como âmbito a sílaba final da palavra quando a sílaba for aberta e acentuada, conforme podemos ver nos dados em (2).

(2)

$\begin{array}{ll}\text { fú } \sim \text { fúe } & \text { 'foi' } \\ \text { peró } \sim \text { peróe } & \text { 'porém' } \\ \text { cosí } \sim \text { cosíe } & \text { 'assim' } \\ \text { lá } \sim \text { láe } & \text { 'lá' }\end{array}$

Há, contudo, situações em que o contexto de aplicação de epêntese é desfeito pelo mapeamento de uma consoante na coda da sílaba alvo, que ocorre no âmbito frasal. Neste âmbito, as palavras terminadas por vogal acentuada em contato com palavras iniciadas por consoante são ambiente para a aplicação da regra de raddoppiamento sintattico (RS), que é uma regra de ressilabação que duplica a primeira consoante da palavra adjacente à palavra oxítona por motivos de ajuste rítmico, conforme os exemplos em (3).

(3)

$\begin{array}{llll}\text { a) fú caro } \rightarrow & \text { [fukkáro] } & \text { b) *[fukekáro] } & \text { 'foi caro' } \\ \text { cosí grande } \rightarrow & \text { [kosiggránde }] & \text { *[kosigegránde] } & \text { 'grande assim' } \\ \text { lá giú } \rightarrow & \text { [laggiúu } & \text { *[lagegiú] } & \text { 'lá embaixo' }\end{array}$

De acordo com os dados em (3-a), não é possível inserir uma vogal entre a seqüência de vogal acentuada e consoante, pois, a partir da aplicação do RS, criou-se uma consoante na coda da sílaba acentuada. Há uma assimilação dos traços da consoante que ocupa o ataque da sílaba seguinte à sílaba acentuada e a conseqüente formação de uma seqüência de segmentos idênticos em (3-b). Esse grupo de consoantes idênticas parece constituir-se 
em uma consoante de ligação dupla, pois a inserção de vogal epentética é bloqueada.

A hipótese de que a geminada seja fonológica no italiano pode ser sustentada a partir da demonstração de outras regras de aplicação bloqueada por essa estrutura, como é o caso da palatalização de velar. Neste caso, a propriedade da inalterabilidade apresenta-se como uma característica de um segmento de ligação dupla, pois, se se tratasse de uma seqüência de segmentos simples idênticos, cada um associado a um nó de tempo, a regra de palatalização poderia aplicar-se à parte dessa seqüência. A inalterabilidade, ou seja, o bloqueio à regras de alteração de traços, impede que regras que têm aplicação a segmentos simples se apliquem a uma parte da geminada.

A regra de palatalização da velar aplica-se na derivação de palavras por sufixação com a adição de morfemas iniciados em /i/ ou na marcação de plural em palavras masculinas pela adição do morfema flexional /-i/ (Nespor, 1993; Scalise, 1994; Dardano \& Trifone, 1995) como podemos ver nos exemplos em (4).

\section{(4)}

a. derivação por sufixação

Stori/k/o $\rightarrow$ stori/t $\int /$ ismo

criti/k/0 $\rightarrow$ criti/t $\int /$ ismo

pudi/k/0 $\rightarrow$ pudi/t $\int / i z i a$

gre/k/o $\rightarrow$ gre/t $\int / i z z a r e$

b. pluralização

stori/t $/ / 1$ 'histórico, historicismo, históricos' criti/ts/i 'crítico, criticismo, críticos' pudi/tS/i 'pudico, pudicícia, pudicos' gre/t5/i 'grego, grecizar, gregos'

A regra de palatalização vista em (4) não se aplica a geminadas, conforme podemos ver em (5).

(5) $\begin{array}{lll}\text { a.derivação por sufixação } & \text { b. pluralização } \\ \text { ba/kk/0 } \rightarrow \text { ba/kk/ico } & \text { ba/kk/i } & \text { 'baco, báquico, bacos' } \\ \text { be/kk/o } \rightarrow \text { be/kk/ime } & \text { be/kk/i } & \text { 'bico, comida para passarinho, bicos' } \\ \text { ri/kk/o } \rightarrow \text { ri } / \text { kk/issimo } & \text { ri } / k k / i & \text { 'riquíssimo, riqueza, ricos' }\end{array}$

Apesar de os sufixos não serem os mesmos listados em (4), os exemplos de flexão de número nos mostram que, mesmo se apresentando a condição fonológica para a palatalização da velar a adjacência à vogal alta /i/ - a aplicação da regra é bloqueada em consoantes geminadas. Mesmo que se pense em uma derivação neológica de ba/kk/o (Baco) para ba/kk/ismo (baquismo), com a adição do mesmo sufixo -ismo adicionado às duas primeiras palavras em (4), stori/tS/ismo e criti/t S/ ismo, não seria posível a aplicação da regra (*ba/ t $\int$ ismo). É possível acreditar que não seja o sufixo o responsável pela aplicação da regra de

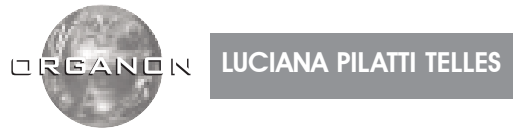

palatalização, mas sim a vogal/i/ que inicia o sufixo, ou seja, a regra de palatalização tem o segmento em sua descrição estrutural e não a morfologia.

A partir destes exemplos, poderíamos concluir que as consoantes duplas do italiano carcterizam-se como geminadas, ou seja, segmentos de ligação dupla controlados pelo OCP. A caracterização das consoantes duplas enquanto geminadas sustenta-se pelo caráter de integridade e de inalterabilidade da consoante dupla, que não é desfeita por inserção de segmento epentético, e pela aplicação da regra de palatalização. O que poderia ser visto como um contra-exemplo à caracterização da geminada é a aplicação da regra de africação a este tipo de segmento.

A regra de africação de oclusivas coronais t/ adjacentes ao [j] é uma regra dependente da estrutura no italiano; há africação da oclusiva coronal quando esta ocupar ataque silábico e estiver adjacente ao glide, conforme podemos ver nos exemplos em (6).

(6) $\begin{array}{ll}\text { ammonito }+ \text { ione } \rightarrow \text { ammoni[tsjo]ne } & \text { 'advertência' } \\ \text { ingiunto }+ \text { ione } \rightarrow \text { ingiun[tsjo]ne } & \text { 'injunção' }\end{array}$

Nos exemplos relacionados em (6), a partir da adição do sufixo/jone/ de formação de substantivo, há a africação da oclusiva coronal da margem do radical do particípio ao qual é adicionado o sufixo. Além dos exemplos listados em (6), em que a consoante que sofre africação é uma consoante simples, podemos listar outros dados, em que a consoante geminada não oferece bloqueio à aplicação dessa regra, conforme podemos ver em (7).

\section{(7)} $\begin{array}{ll}\text { corretto+ione } \rightarrow \text { corre[tstsjo]ne } & 1 \\ \text { descritto }+ \text { ione } \rightarrow \text { descri[tstsjo]ne } & \text { 'correção' } \\ \text { 'descrição' }\end{array}$

Os exemplos em (7) contrariam a hipótese de que o princípio responsável pelo bloqueio à aplicação de regras a geminadas é a Restrição de Ligação. Por este princípio, a geminada não poderia sofrer a aplicação de uma regra que faz referência a segmentos de ligação simples, como é o caso da regra de africação, que faz referência à unidade esqueletal que ocupa ataque silábico, modificando os traços de /t/ que precede glide. As formas corre[tsts]ione e descri[tsts]ione, geradas a partir da sufixação das bases constituídas pelos particípios verbais corretto (corrigido) e descritto (descrito), 
por apresentarem geminadas transparentes à aplicação de regras, contra-exemplificam a proposta de Hayes (1986) segundo a qual geminadas que sofrem a aplicação de regras de mudança de traços são falsas geminadas.

A argumentação de Hayes é baseada nos dados do tigrinya, língua que apresenta geminadas verdadeiras, ou seja, segmentos de ligação dupla, e geminadas falsas, que são pares de segmentos simples idênticos adjacentes. Partimos do pressuposto de que as geminadas que sofrem a aplicação da regra em (7) são geminadas resultantes de processos assimilatórios, ou seja, verdadeiras geminadas, assim como algumas das geminadas do tigrinya $^{2}$.

A assimilação, a nosso ver, ocorre antes da formação do substantivo pela adição do sufixo /jone/, e a base para formação do substantivo apresenta geminada verdadeira resultante de processo assimilatório. Conforme dito anteriormente, a base para a formação dos substantivos relacionados em (6) e (7) é o particípio verbal formado pela adição do sufixo - to ao radical verbal. Nos particípios em que se apresentam geminadas, o radical verbal apresenta consoante na coda de sua última sílaba, assim como se apresentavam no latim, em que o particípio verbal apresentava seqüência de consoantes, conforme podemos ver em (8)

(8)

$\begin{array}{lll}\text { Formas latinas } & \text { Formas italianas } & \\ \text { Correc\#to } & \text { corretto } & \text { 'corrigido' } \\ \text { Scrip\#to } & \text { scritto } & \text { 'escrito' } \\ \text { lec\#to } & \text { letto } & \text { 'lido' } \\ \text { dic\#to } & \text { detto } & \text { 'dito' } \\ \text { fac\#to } & \text { fatto } & \text { 'feito' }\end{array}$

Nos exemplos em (9), podemos ver que, no italiano, os radicais verbais dispõem de consoante na coda (cf. Sensini, 1997, p. 292).

\section{(9)}

$\begin{array}{lll}\text { Corregg\#to } & \text { corretto } \\ \text { Descriv\#to } & \text { descritto }\end{array} \quad$ 'descrigido'

É fato, pois, a existência de consoantes na margem direita dos radicais verbais no italiano que, na derivação, passam a ser geminadas, de acordo com o sufixo que lhes é adicionado. A formação de particípio no italiano ocorre também pelo acréscimo de outros sufixos: -ato, -uto e -ito, que são combinados ao radical verbal de acordo com a conjugação do verbo, conforme os exemplos em (10).
(10)

\begin{tabular}{|c|c|c|}
\hline Formas infinitivas & particípios & \\
\hline (primeira conjugação) & & \\
\hline guardare & guard\#ato & 'olhar' 'olhado' \\
\hline nevicare & nevic\#ato & 'nevar' 'nevado' \\
\hline telefonare & telefon\#ato & 'telefonar' 'telefonado' \\
\hline (Segunda conjugação) & & \\
\hline bere & bev\#uto & 'beber' 'bebido' \\
\hline vedere & ved\#uto ${ }^{3}$ & 'ver' 'visto' \\
\hline (terceira conjugação) & & \\
\hline udire & ud\#ito & 'ouvir' 'ouvido' \\
\hline partire & part\#ito & 'partir' 'partido' \\
\hline mentire & ment\#ito & 'mentir' 'mentido' \\
\hline
\end{tabular}

Os particípios relacionados em (10) são regulares no italiano, ao contrário dos particípios relacionados em (9), formados pela adição do sufixo -to ao radical. $\mathrm{O}$ sufixo - to combina-se a radicais de verbos de primeira e de segunda conjugação, como nos mostram os dados em (11).

(11)

$\begin{array}{lll}\text { Formas infinitivas } & \text { Particípios } & \\ \text { (primeira conjugação) } & & \\ \text { fare } & \text { fatto } & \text { 'fazer, feito' } \\ \text { trarre } & \text { tratto } & \text { 'extrair, extraído' } \\ \begin{array}{l}\text { (Segunda conjugação) } \\ \text { correggere }\end{array} & \begin{array}{l}\text { corretto } \\ \text { scrivere }\end{array} & \text { 'corrigir, corrigido' } \\ \text { scritto } & \text { escrever, escrito' }\end{array}$

O sufixo -to, conforme vimos, não tem associação restrita a uma única conjugação verbal. Pelo fato de as sociar-se a radicais verbais terminados em consoante, desencadeia um processo assimilatório, criando uma verdadeira geminada, em nosso entender. De acordo com o princípio da Restrição de Ligação, sendo verdadeiras geminadas as geminadas componentes dos particípios irregulares formados pela adição do sufixo -to, deveriam bloquear a atuação da regra de africação.

O que pudemos constatar é que apenas o sufixo -ione provoca africação, pois outros sufixos iniciados por glide não provocam africação da oclusiva coronal /t/ a eles adjacente, conforme os dados em (12).

\section{(12)}

carretto+[j]ere $\rightarrow$ carre[ttje]re *carre[ttsje]re 'condutor da carreta' argento+[j]]ere $\rightarrow$ argen[tje]re *argen[tsje]re 'artesão que trabalha com prata' moneta+[j]ere $\rightarrow$ mone[tje]re *mone[tsje]re 'fabricante de moedas'

Como dizíamos anteriormente, a africação é uma regra dependente da estrutura; é uma regra segmental de mudança de traços que faz referência 
ao âmbito silábico do segmento ao qual se aplica. Assim considerada, deveria ter aplicação sempre que se cumprisse a condição de adjacência da oclusiva coronal / $\mathrm{t} /$ ao glide /j/, o que não ocorre. De acordo com os dados relacionados em (11), a adjacência da oclusiva coronal ao glide não é suficiente para que a regra se aplique. Nesses exemplos, não apenas a geminada, mas também a consoante simples oferece bloqueio à aplicação da regra de africação. Considerados estes dados, podemos supor que a africação da geminada em corre/tsts/ione e em descri/tsts/ione seja um efeito resultante da implementação fonética na articulação da oclusiva coronal seguida por vogal alta, como considera Clements (1999) acerca da africação ${ }^{4}$. Entretanto, o efeito de estridência estaria restrito a um tipo de sufixo no italiano.

Segundo Scalise (1994), a regra de africação é uma regra de reajuste que se aplica após a aplicação da regra morfológica (de adição do sufixo /jone/). A Condição de Aplicabilidade Uniforme proposta por Shein \& Steriade (1986), segundo a qual regra e gatilho devem ter descrição estrutural uniforme, tem sustentação nestes exemplos de transparência da geminada se se considera que regra e segmento apresentam a mesma descrição estrutural referente à informação morfológica. Desse modo, podemos considerar que as regras de assimilação na adição do sufixo /jone/ a bases com geminadas façam referência à base, independentemente do tipo de ligação que apresenta o segmento que sofrerá o processo $^{5}$. Supondo que a regra não faça referência ao tipo de ligação que apresenta o segmento que sofrerá sua aplicação, apenas a Condição de Aplicabilidade Uniforme tem sustentação, visto que pela Restrição de Ligação, uma regra que tem aplicação a segmentos simples não se aplica a segmentos geminados.

Assumindo esta explicação para a transparência das geminadas na aplicação de regras de espraiamento de traços como na aplicação da regra de africação, que forma descri/ttsjone/, a opacidade da geminada à palatalização de velares também deve ser explicada com base na Condição de Aplicabilidade Uniforme. Nesse caso, a regra não se aplicará por não fazer referência à morfologia do radical, mas ao segmento. Nesse sentido, sendo uma regra de nível segmental, não se aplica a geminadas por não ter descrição estrutural para segmento duplo.

Podemos concluir até este ponto de nossa

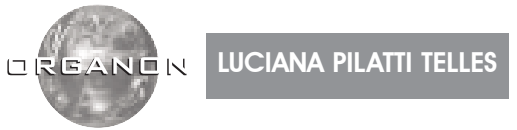

análise que, considerada a Condição da Aplicabilidade Uniforme como condição atuante no controle de aplicação de regras a geminadas, a africação de geminadas na derivação de nomes a partir da adição do sufixo /jone/ a particípios verbais é permitida pela descrição morfológica uniforme que apresentam regra e alvo, o que não descaracteriza a geminada. Assumindo ainda a análise de africadas de Clements (1999), podemos acreditar que a africação ocorreu em um nível fonético e foi lexicalizada restrita a um único sufixo no italiano.

\section{A RELAÇÃO ENTRE SÍlABA, ACENTO E GEMINAÇÃO NO ITALIANO}

Nossa hipótese referente à segunda questão, concernente à relação existente entre geminação e acento no italiano é de que o acento primário seja atribuído sensivelmente à distribuição das geminadas no italiano. Buscando sustentar esta hipótese testaremos as hipóteses de Condição de Rima Forte (Vogel, 1982) e de Condição de Formação de Pés (D’Imperio \& Rosenthal, 1999), segundo as quais a geminação é motivada por condição de boa-formação prosódica, e a hipótese de Sensibilidade à Quantidade (Sluyters, 1990), segundo a qual o acento é atribuído sensivelmente à constituição silábica no italiano.

$\mathrm{O}$ italiano apresenta consoante geminada nos contextos em que o latim apresentava vogal longa. A quantidade da vogal e a atribuição do acento estão relacionadas. Nos exemplos do latim listados em (13), na sílaba em que há vogal longa, há atribuição de acento primário, pois o acento, no latim, era atribuído à penúltima sílaba, se fosse pesada.

$\begin{array}{lll}\text { (13) } & & \\ \text { Formas latinas } & \text { Formas italianas } & \\ \text { sūcu } & \text { súcco } & \text { 'suco' } \\ \text { brūtu } & \text { brútto } & \text { 'feio' } \\ \text { tōtu } & \text { tútto } & \text { 'tudo' } \\ \text { cūpa } & \text { cóppa } & \text { 'copa' }\end{array}$

Nos exemplos em (13), podemos ver que também no italiano são acentuadas as sílabas pesadas. Segundo Vogel (1982), vogais longas não são subjacentes no italiano. Podemos supor que, em não sendo subjacentes as vogais longas no italiano, as formas succo, brutto, tutto e coppa tenham sido geradas pelo preenchimento de um nó esqueletal vazio associado à coda da sílaba que no latim apresentava um nó de vogal. Em (14), temos a 
representação deste processo.

(14)

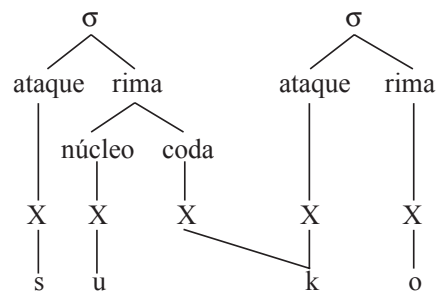

Tal processo pode ser interpretado, conforme sugerem Saltarelli (1983), Vogel (1982) e Chierchia (1986) como condição de boaformação silábica. Por esta condição, sílabas leves acentuadas são mal-formadas. Desse modo, as sílabas que eram acentuadas no latim e que permaneceram acentuadas no italiano mantiveramse pesadas.

Podemos verificar também casos de geminação precedendo o glide, que, de acordo com Schein \& Steriade (1986) e Borrelli (2002), formaram-se pela adjacência de segmentos simples a glides. Nos exemplos relacionados em (15), a sílaba que precede consoante seguida de glide é acentuada no latim.

(15)

Formas latinas Formas italianas

\begin{tabular}{|c|c|c|}
\hline fólia $>*^{*}$ follia $^{6}$ & fóglia $[\mathrm{fó} K \mathrm{Ka}]^{7}$ & 'folha'8 \\
\hline hábeat $>*$ abbia & ábbia & 'tenha' \\
\hline$* \mathrm{si}$ & amia [ [ímmja] & acaco \\
\hline eat $>*_{\text {sappia }}$ & sáppia & iba’ \\
\hline
\end{tabular}

Nos exemplos relacionados em (15), nas formas latinas, a sílaba acentuada não é pesada, mas é pesada nas formas italianas. Podemos supor que a geminação nestas formas se apresente pelo cumprimento à condição de boa-formação silábica que requer que sílabas acentuadas sejam pesadas (cf. Saltarelli, 1970 e 1983 e Vogel, 1982). Coincidentemente, há glide nas formas elencadas, mas não acreditamos que seja o gatilho para geminação, pelo fato que, segundo Nespor (1993), os segmentos constituintes do ditongo crescente estão associados ao núcleo silábico.

Há relação entre acento e geminação também nas formas italianas relacionadas por Borrelli (2002) que apresentam geminadas em sílabas às quais no latim recaía acento primário, conforme podemos ver em (16).
(16)

Formas latinas Formas italianas

$\begin{array}{lll}\begin{array}{ll}\text { Átomu } \\ \text { Legítimu }\end{array} & >\text { áttimo } & \text { 'instante' } \\ \text { Fémina } & >\text { legíttimo } & \text { 'legítimo' } \\ \text { Ábacu } & >\text { ábbaco } & \text { 'fêmea' } \\ \text { Máchinaco' } & >\text { mácchina } & \text { 'máquina' } \\ \text { Públicu } & >\text { púbblico } & \text { 'público' } \\ \text { Propágine } & >\text { propággine } & \text { 'descendência' }\end{array}$

Os casos de geminação apresentados nos dados listados em (16) podem ser explicados pela Condição de Rima Forte, segundo a qual, é prosodicamente bem-formada a sílaba acentuada que apresenta rima ramificada. Vogel (1982) \& Chierchia (1986) justificam a geminação e a aplicação de $R S$ a partir da consideração dessa condição. Neste sentido, em macchina, por exemplo, em respeito à condição, a sílaba passou a apresentar um nó vazio, conforme representação de sua primeira sílaba (ma) em (17).

(17)

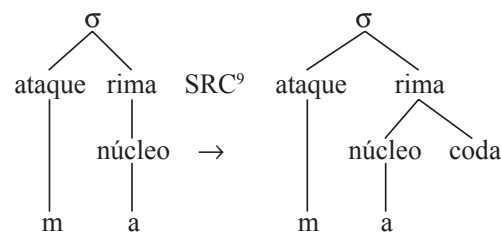

Em função da atuação da Condição de Rima Forte, conforme a representação em (17), a rima passa a dominar, além do núcleo, uma posição esqueletal não-preenchida, ou seja, um nó vazio, que terá preenchimento pelo espraiamento dos traços do segmento adjacente. Em (18), temos a representação desse processo.

(18)

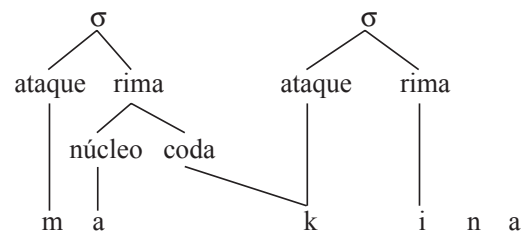

De acordo com a representação em (18), pela Convenção do Nó Vazio (Ingria, 1980; Vogel, 1982; Saltarelli, 1983; Chierchia, 1986), a coda da primeira sílaba em macchina é preenchida pelos traços da consoante que preenche o ataque da sílaba que lhe é seguinte. A consideração de boa-formação prosódica 
prevê que o acento no italiano é distribuído por contagem de sílabas e que a sílaba que o porta deve ser pesada. Chierchia (1986), restringe o preenchimento da coda por consoante, pela definição de que o alongamento de vogal, não distintivo no italiano, tem aplicação no pós-léxico, ao passo que a geminação de consoantes é lexical.

De acordo com Kager (1995) e D'Imperio \& Rosenthal (1999), em ambientes acentuados há aumento da quantidade segmental. Se considerada a condição de boa-formação de pés, proposta por D'Imperio \& Rosenthal, que exige que os pés sejam bimoraicos, em uma palavra como sèppelíre, devese considerar que o pé tenha dominância à direita $\mathrm{e}$ que a última sílaba seja extramétrica, do mesmo modo como em àccadémia e pèllegríno, em que há atribuição de acento secudário à sílaba acentuada. Essa consideração, porém, não dá conta dos dados de geminação seguindo acento primário, em que os pés têm cabeça à esquerda, a menos que se considere que há no italiano um inventário de pés, como propõe Marotta (1999).

Considerando sincronicamente o alongamento, a justificativa prosódica para inserção de nó consonântico ou de nó vocálico no interior da palavra está relacionada ao acento paroxítono, no caso de alongamento de vogais e geminação de consoantes, e ao acento oxítono, no caso de geminação de consoantes. Pela análise de D' Império \& Rosenthal (1999), o ritmo do italiano é organizado em pés trocaicos de dominância à esquerda. $\mathrm{O}$ alongamento de vogal ou a geminação de consoantes na penúltima sílaba acentuada garante sua boa formação prosódica em palavras dissílabas, pois a última sílaba é extramétrica. De acordo com sua análise, no caso de palavras trissílabas, a penúltima sílaba não precisa ser pesada, pois o pé é constituído por duas sílabas. Os dados, porém, nos mostram que a hipótese de Sluyters (1990) é mais adequada ao tratamento da distribuição do acento primário no italiano. Em (95), podemos ver sua proposta em relação ao algoritmo de atribuição de acento primário no italiano, de acordo com o qual o acento é atribuído sensivelmente ao peso silábico.

(19)

Construa (não-iterativamente) da direita para a esquerda (* .) se possível. $\mathrm{L}$

De outro modo, construa $(*)$ ou (.)

$$
\mathrm{H} \quad \mathrm{L}
$$

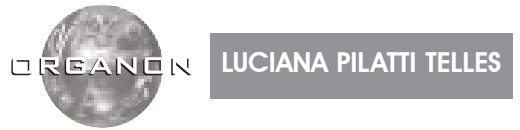

Segundo Sluyters, uma evidência para a sensibilidade ao peso é que em contexto de geminação em final de palavra, o nó de consoante associado à coda silábica tem preenchimento pelo espraiamento dos traços da consoante que lhe é adjacente. Com base na análise de Sluyters, acreditamos que o nó associado seja um C-slot e não um V-slot, porque apenas sílabas fechadas por consoante são pesadas no italiano. Por esta análise, podemos, então, justificar a existência de segmentos de ligação dupla verificando a distribuição do acento primário. Em palavras como corretto e scritto, por exemplo, podemos verificar o acento precedendo geminada.

De modo a testar a sustentação da hipótese de sensibilidade à quantidade, devemos considerar, além do acento paroxítono, o acento proparoxítono. Nas palavras relacionadas em (20), há geminação fechando sua antepenúltima sílaba.

$\begin{array}{ll}\mathbf{( 2 0 )} & \\ \text { áttimo } & \text { 'instante' } \\ \text { legíttimo } & \text { 'legítimo' } \\ \text { fémmina } & \text { 'fêmea' } \\ \text { ábbaco } & \text { 'ábaco' } \\ \text { mácchina } & \text { 'máquina' } \\ \text { púbblico } & \text { 'público' } \\ \text { propággine } & \text { 'descendência' }\end{array}$

A partir da relação de exemplos em (20), podemos considerar confirmada a hipótese de acento sensível à quantidade. Há contextos, contudo, em que o acento primário não é atribuído à sílaba fechada por parte da consoante geminada, como nos exemplos relacionados em (21).

\section{(21)}

$\begin{array}{ll}\text { a) al.le.gá.to } & \text { 'anexo' } \\ \text { b) fat.to.rí.no } & \text { 'auxiliar' } \\ \text { c) pub.bli.ci.tá.rio } & \text { 'publicitário' } \\ \text { d) fal.lí.to } & \text { 'falido' } \\ \text { e) fat.tó.re } & \text { 'artífice, autor' }\end{array}$

Os dados relacionados em (21) não enfraquecem a análise de sensibilidade ao peso silábico. Em (97 - a, b e c), o acento é atribuído à penúltima sílaba porque, no italiano, são acentuadas apenas as três últimas sílabas da palavra e, nesses casos, a sílaba pesada está além da antepenúltima sílaba. Nos exemplos em (97-d, e), o acento é atribuído à penúltima sílaba porque os sufixos adicionados às bases são acentuados e mudam a distribuição do acento na palavra. 
Diante dos exemplos relacionados em (21), considerada a hipótese de Condição de Rima Forte, segundo a qual a sílaba acentuada deve ser pesada, a sílaba acentuada deveria ser pesada e, no entanto, não o é. Com relação à hipótese de D'Imperio \& Rosenthal (1999), se consideramos que a geminação ocorre em cumprimento à condição de boa-formação de pés bimoraicos, os dados em (22) nos indicam a possibilidade de escansão em pés bimoraicos, porém, os pés formados não são troqueus, mas iambos. Pela hipótese de D'Imperio \& Rosenthal, que ora testamos, palavras como al.le.gá.to e fat.to.rí.no, por exemplo, apresentam vogal longa subjacente na penúltima sílaba e sua última sílaba é extramétrica. Considerada a última sílaba extramétrica, a escansão em pés de al.le.gá.to e fat.to.rí.no pode ser vista em (22).

\section{(22)}

$\begin{array}{ll}\text { al. le. ga }<\text { to }> & \text { fat. to.ri. }<\text { no }> \\ \mu \mu \mu \mu & \mu \mu \mu \mu \\ \left(^{*}\right)\left(.^{*}\right) & \left(^{*}\right)\left(.^{*}\right)\end{array}$

Nas escansões em (22), os pés formados são iambos. Se se considerasse licenciada a última sílaba, o pé formado seria trocaico, mas a escansão em pés bimoraicos, defendida por D' Imperio \& Rosenthal (1999), não teria sustentação. Em (23), a partir da escansão de spázzola (escova) e de fávola (fábula), podemos notar que a definição de formação de pés bimoraicos não é uniforme.

$\begin{array}{lll}\text { (23) } & & \\ \text { spaz. } & \text { zo. }<\text { la }> & \text { fa. vo. }<\text { la }> \\ \mu \mu & \mu & \mu \mu \\ (*) & (.) & (* .)\end{array}$

Em (23), a escansão em pés de spázzola apresenta pé degenerado, a menos que se considere o mapeamento da última sílaba. Em fávola, porém, devemos considerar extramétrica a última sílaba para que a condição de formação de pés bimoraicos se cumpra. Nestes dados, considerada a extrametricidade da última sílaba, a hipótese de formação de pés bimoraicos não se sustenta.

A vantagem da proposta de Sluyters (1990) em relação à proposta de D'Imperio \& Rosenthal (1999), está na possibilidade de explicação de geminação em contexto não- acentuado, uma vez que a hipótese da Condição de Rima Forte não dá

conta deste dado.

A consideração de nó vazio a ser preenchido não é contrária à consideração de sensibilidade à quantidade. Assim como nos possibilita explicar os casos de geminação no italiano em que no latim havia duração vocálica, nos ajuda a explicar a acentuação na última sílaba. Não assumimos, assim como Sluyters, a Condição de Rima Forte, pois considerada esta condição, deveríamos ter também alongamento vocálico em final de palavra, o que não se observa no italiano.

\section{A NATUREZA DERIVACIONAL DAS GEMINADAS NO ITALIANO}

A ligação dupla característica do segmento geminado é verificada nas propriedades que o segemento apresenta pela atuação do Pincípio do Contorno Obrigatório, do Princípio do NãoCruzamento de Linhas de Associação e da Condição de Aplicabilidade Uniforme. Seus nós de tempo estão distribuídos entre duas sílabas e sua constituição está em conformidade com as condições de coda e de ataque nessa língua. Sua distribuição entre coda e ataque silábico faz pesar a sílaba que tem a coda preenchida por parte do segmento, o que faz com que o acento primário lhe seja atribuído.

Conforme exposto na defesa desta hipótese, oxítonas têm acento atribuído pelo mapeamento de um vazio esqueletal que tem preenchimento na sufixação e na geminação em âmbito frasal. Nos dados relacionados em (24), podemos observar o preenchimento do nó vazio em final de palavras quando há derivação.

$\begin{array}{llll}\text { (24) } & & & \\ \text { Base } & \text { Palavra derivada } & \\ \text { Forlí } & \text { forlivese } & \text { 'Forli' (cidade italiana) } & \text { 'nascido em Forli' } \\ \text { Perú } & \text { peruviano } & \text { 'Peru' } & \text { 'peruano' } \\ \text { Caffé } & \text { caffetteria } & \text { 'cafe' } & \text { 'cafeteria' } \\ \text { Ragú } & \text { ragutiera } & \text { 'guisado' } & \text { 'baixela para guisado' }\end{array}$

De acordo com os dados relacionados em (24), o preenchimento do vazio esqueletal na derivação a partir de bases oxítonas apresenta traços de consoante. Considerados os adjetivos de proveniência (forlivese e peruviano), por exemplo, o paradigma preveria a adição dos sufixos - ese e ano ou-iano se a base não fosse oxítona, conforme podemos ver em (25). 


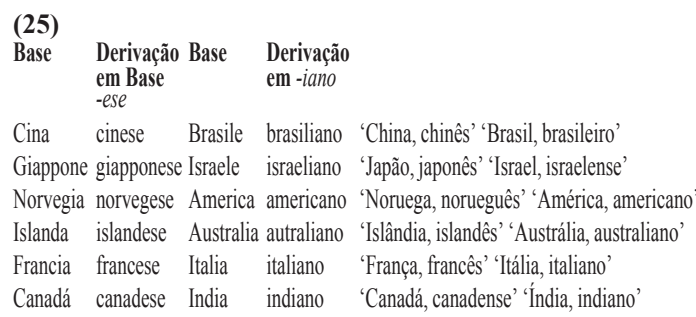

As bases relacionadas em (25) não são oxítonas. Não sendo oxítonas as bases, não são inseridos traços de consoante e o sufixo adicionado inicia sempre por vogal. Não são atestadas derivações a partir de bases oxítonas em que seja inserida uma vogal e não uma consoante, por isso, nossa hipótese de que o vazio esqueletal seja preenchido por traços de consoante se confirma.

Nossa última hipótese é referente à natureza de algumas geminadas. Acreditamos que nem todas as geminadas sejam derivadas por regras, mas que algumas estejam disponíveis lexicalmente. A confirmação desta hipótese depende da consideração da pressuposição de que a geminada não seja determinada prosodicamente, mas que o acento seja distribuído sensivelmente ao peso silábico. Em (26) listamos alguns dados de palavras em que as geminadas não são resultantes de regra de assimilação ou de preenchimento de traços.

$\begin{array}{ll}\text { (26) } & \\ \text { anno } & \text { 'ano' } \\ \text { sonno } & \text { 'sono' } \\ \text { bella } & \text { 'bela' } \\ \text { stella } & \text { 'estrela' }\end{array}$

As palavras relacionadas em (26) foram mantidas do léxico latino. Além destas palavras, se considerarmos que as formas de particípio irregular estejam listadas no léxico como palavras, podemos supor que as geminadas em scritto, corretto, fatto, letto, commesso e rotto estejam pré-especificadas lexicalmente e não sejam, sincronicamente, derivadas no italiano, o que sustenta parcialmente nossa última hipótese.

Confirmadas, pois, nossas hipóteses de que (1) a geminada é fonológica no italiano, (2) o acento primário lhe é sensível, (3) há especificação para um slot na geminação, (4) o slot é especificado para traços de consoante, e, confirmada parcialmente, a hipótese de que (5) algumas geminadas sejam especificadas lexicalmente, não sendo todas as geminadas derivadas por regras, passamos, na seção seguinte, às considerações finais.

\section{CONSIDERAÇÕES FINAIS}

Com base nos dados relacionados, podemos acreditar que a geminação no italiano seja fonológica - e não puramente fonética, como supõe Saltarelli (1970 e 1983) - , tendo em vista sua distintividade e bloqueio à atuação de regras segmentais. Um outro argumento favorável ao caráter fonológico da geminada no italiano é a atribuição de acento que, conforme mostramos, apoiados na análise de Sluyters (1990), é sensível ao peso silábico. Com relação às questões que nos guiaram neste artigo, relacionamos, a seguir, algumas conclusões.

Quanto à primeira questão, por considerarmos, assim como Vogel (1982), Chierchia (1986) e Nespor (1993), que as vogais longas não são subjacentes no italiano, pares opositivos nos indicam que a geminação é subjacente no italiano. Desta consideração, deriva a resposta à segunda questão: sendo subjacente, não é, diferentemente do que propõe Saltarelli (1970), efeito fonético da atribuição do acento, mas o acento lhe é sensível por ser o acento no italiano sensível à quantidade.

A consideração de nó vazio, que explica a acentuação na sílaba final, nos aponta a terceira questão: há alguma especificação do nó de tempo em termos de vogal ou consoante? Nossa resposta a essa questão está baseada na proposta de Sluyters (1990), segundo a qual o nó vazio é especificado como nó de consoante, pois não há vogal longa na última sílaba acentuada.

Quanto à última questão, conforme vimos ao longo deste artigo, algumas geminadas que se apresentam em palavras italianas foram mantidas do léxico latino. Acreditamos que essas geminadas não sejam derivadas, mas lexicalmente especificadas como geminadas. Consideramos ainda que geminadas que se apresentaram no italiano em contextos em que se apresentava vogal longa ou acento no latim também sejam especificadas como geminadas, sendo derivadas apenas as geminadas que se formaram, e que ainda se formam, por assimilação como aquelas que constutuídas a partir da prefixação. Nesse sentido, todas elas, derivadas ou não, são fonológicas. Diferentemente do que consideram D'Imperio \& Rosenthal (1999), para quem a geminação na frase é motivada pelo acento. 
concordamos com Sluyters (1990), segundo o qual a motivação para $R S$ é subjacente.

Não pudemos, neste estudo, analisar a duração em contextos não-acentuados. Do fato de supormos que a geminação não seja efeito do acento, decorre nossa crença na duração da geminada mesmo em contexto não acentuado. Cremos, porém, que estes contextos mereçam uma análise empírica que sustente nossa hipótese. A duração da geminada em contexto não acentuado seja ela derivada, como em attraversare, seja não derivada, como em cappotto, permanece neste estudo como uma hipótese a ser ainda confirmada através da análise acústica de dados de fala italiana.

Uma análise que permanece em aberto é a análise da formação de particípios irregulares no italiano. Um estudo à luz da Fonologia Lexical pode ainda ser desenvolvido no sentido de investigar a natureza da geminação em formas como letto, rotto e messo, por exemplo e de esclarecer se estas formas estão preespecificadas nestas palavras já listadas no léxico profundo (o que poderia confirmar nossa última hipótese) ou se se formam por regras na formação, também por regras, deste tipo de palavra. Uma outra possibilidade de análise seria a consideração da atuação de uma restrição para garantir a realização de geminadas nas formas relacionadas.

\section{REFERÊNCIAS BIBLIOGRÁFICAS}

BORRELLI, D. Raddoppiamento Sintattico in Italian: A Synchronic and Diachronic CrossDialetal Study. Routledge, New York \& London, 2002.

CANEPARI, L. Manuale di Pronuncia Italiana. Bologna: Zanichelli, 2000.

CHIERCHIA, G. Length, Syllabification and the Phonological Cycle in Italian. Journal of Italian Linguistics 8: 5-34, 1986.

CLEMENTS, G. Affricates as Noncontoured Stops. In: FUJIMURA, O; JOSEPH,. B. D.; PALEK, B. (eds.) Proceedings of LP '98. Charles University in Prague, The Karolinum Press, p. 271-299, 1999. CLEMENTS, G.; HUME, E. Internal Organization of Speech Sounds. In: GOLDSMITH, J. (org.) The Handbook of Phonological Theory. London: Blackwell, 1995.

DARDANO, M; TRIFONE, P. Gramática Italiana. Con nozioni di Lingüistica. Bologna: Zanichelli, 1995.
D'IMPERIO, M. P.; ROSENTHAL, S. Phonetics and Phonology of Main Stress in Italian. In: Phonology 16, p. 1-28, 1999.

FALUSCHI, S; DI BENEDETTO, M. G. Accoustic Analysis of Singleton and Geminates Affricates in Italian. WEB-SLS. The European Student Journal of Language and Speech, 2001.

GIOVANARDI, M.; DI BENEDETTO, M. G. Accoustic Analysis of Singleton and Geminate Fricatives in Italian. WEB-SLS. The European Student Journal of Language and Speech, 1998.

HAYES, B. Inalterability in CV phonology. Language 62, n.2, 321-351, 1986.

INGRIA, R. Compensatory Lenghtening as a Metrical Phenomenon. Linguistic Inquiry, 11, 465495,1980.

KAGER, R. Metrical Theory of Word Stress. In: GOLDSMITH, J. (org.) The Handbook of phonological Theory. London: Blackwell, 1995

KAGER, R.; DEN OS, E. Extrameticality in spanish and in italian. Lingua 69, 23-48, 1986.

KIRCHNER, R. Geminate Inalterability and Lenition. Language, vol. 17, no. 3, 2000.

MATTEI, M.; DI BENEDETTO, M. G. Accoustic Analysis of Singleton and Geminate Nasals in Italian. WEB-SLS. The European Student Journal of Language and Speech, 2000.

MAROTTA, G. Degenerate Feet nella Fonologia metrica dell'italiano. In: Fonologia e Morfologia dell'Italiano e dei Dialetti d'Italia - Atti del XXXI Congresso. Roma: Bulzoni, 1994.

NESPOR, M. Le Strutture del Linguaggio: Fonologia. Bologna: Il Mulino, 1993.

NESPOR, M.; VOGEL, I. Prosodic Phonology (Studies in Generative Grammar 28 Dordrecht: Foris Publications. (cap. 1 e 5), 1986.

SALTARELLI, M. A Phonology of Italian in a Generative Grammar. The Hague: Mouton, 1970.

. The Mora Unity in Italian Phonology. Folia Linguistica - Acta Societatis Linguisticae Europeae.7-34. The Hague: Mouton Publishers, 1983.

SCALISE, S. Le Strutture del Linguaggio: Morfologia. Bologna: Il Mulino, 1994.

SCHEIN, B.; STERIADE, D. On Geminates. Linguistic Inquiry, volume 17, 1986, p. 691-744.

SENSINI, Marcello. La Grammatica della Lingua Italiana. Milano: Oscar Mondadori, 1997.

SLUYTERS, W. Length and Stress Revisited: a Metrical Account of Dipthongization, Vowel Lengthening, Consonant Gemination and Word- 
final Vowel Epenthesis in Modern Italian Italian. Probus 21, 65-102, 1990.

VOGEL, I. La sillaba come unità fonologica. Bologna: Zanichelli, 1982.

. Phonological Evidence for Level Ordering in Italian Word Formation. Acta linguistica 36. 245 260, 1986.

WILTSHIRE, C.; MARANZANA, E. Geminates and Clusters in Italian and Piedmontese: a case for OT ranking. Paper presented at $28^{\text {th }}$ Linguistic Symposium on Romance Languages, Pennsylvania State University, 1998.

\section{Notas:}

${ }^{1}$ Estamos adotando a transcrição de africadas geminadas proposta por Canepari (1999).

${ }^{2}$ In the spreading model of assimilation, an assimilation rule always gives rise to multilinked nodes in its output. Notice, for exemple, that in the output of a total assimilation rule a single root node is linked to two skeletal positions. It will be recalled that this type of representation is identical to the one proposed earlier for underlying long segments. The spreading model of assimilation predicts, therefore, that geminates derived by assimilation rules should be formally indistinguishable from underlying geminates with regard to later stages of a phonological derivation. (Clements \& Hume, 1995, p. 259)

${ }^{3}$ Há também a formação do particípio visto para o verbo vedere ${ }^{4}$ Clements (1999, p. 287) considera que a africação não seja resultante da assimilação de traços, mas da inserção de traços 'triggered by a phonology-phonetics mismatch' na pronúncia de $[\mathrm{t}]$ adjacente à vogal alta ou glide.

${ }^{5}$ Segundo Nespor (1993, p. 146), a regra de africação na formação de nomes a partir da sufixação é uma regra lexical no italiano. A autora explica que o sufixo -ione está em um estrato anterior ao estrato dos sufixos que não provocam africação.

${ }^{6}$ Asterisco indica forma hipotética.

${ }^{7}$ Corforme Chierchia (1986) e Wiltshire \& Maranzana (1998), palatais são inerentemente geminadas.

8 Borrelli (2002) está considerando palatais como subjacentemente longas.

${ }^{9}$ Condição de rima forte. 